\title{
Creating an anti-ageist healthcare system to improve care for our current and future selves
}

\author{
COVID-19 has highlighted pervasive ageism and the interconnectedness of individuals and societies. This \\ Comment discusses how creating an anti-ageist healthcare system will improve health outcomes for our current \\ and future selves.
}

\author{
Sharon K. Inouye
}

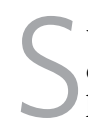
uperimposed on the rapid aging of our populations globally, COVID-19 has provided an intensive stress test for our aging populations, exposing pervasive ageism in society and healthcare systems. Stark age-related inequities in healthcare delivery and outcomes have come to the forefront of international attention and discourse. Despite this spotlight, the issues 'uncovered' by COVID-19 have been long-standing, deeply entrenched and steadily increasing over time ${ }^{1}$. This Comment will serve to highlight key areas where ageism has adversely impacted our healthcare system, leading to poorer clinical outcomes.

Here, ageism is defined as age-related discrimination, including explicit age cut-offs for treatment or resource allocation, or implicit age-related biases which limit access or create barriers to health care. At a fundamental level, ageism results in generally poorer health care leading to adverse outcomes and increased mortality. Well documented in 149 previous studies ${ }^{1}$, ageism leads to barriers in access or denial of healthcare services and treatments, with age being the primary factor determining who receives certain procedures and treatments. In a landmark study of over 9,000 hospitalized patients preceding COVID-19, healthcare professionals were significantly more likely to withhold life-sustaining treatments for older compared with younger persons, even after controlling for prognosis and patient preferences ${ }^{2}$, a practice that has persisted to date. Ageism has also led to inadequate or inappropriate care and decreased or delayed access to healthcare services, resulting in decreased survival, poorer quality of life, increased cognitive and functional impairment, and increased medication noncompliance, emergency visits and hospitalizations ${ }^{1}$.

Lack of awareness of unique aspects of disease presentation in older adults can lead to missed or delayed diagnoses. Most physicians and nurses are not aware of the frequent atypical presentations of many diseases in older adults. At least one third of serious infections do not present with fever in seniors ${ }^{3}$; moreover, acute myocardial infarction typically presents with nonspecific features rather than with the classic symptom of chest pain ${ }^{4}$. Dizziness, falls, delirium, decreased appetite and failure-to-thrive are common nonspecific presentations of acute illness in older adults. Delayed or missed diagnoses can lead to serious health complications, including death.

Older adults are at strikingly increased risk of adverse drug reactions ${ }^{5}$, with frequent polypharmacy and drug-drug and drug-disease interactions. Moreover, certain classes of medications, identified as potentially inappropriate medications (PIMs), have an unfavorable risk-benefit ratio for older adults, yet are prescribed to over 23\% (ref. ${ }^{5}$ ). Published in 1991 and regularly updated, the Beers criteria ${ }^{6}$ are designed to improve appropriate use of medications for older adults by reducing PIMs. The criteria also provide guidelines that emphasize dosage reductions or deprescribing medications that are unnecessary, thereby reducing the problems of polypharmacy and adverse drug reactions. These are key areas to address in enhanced geriatric training for all healthcare professionals.

Improved education and training of healthcare professionals in the unique aspects of diagnosis and treatment in older adults will help to combat ageism in health care. Most healthcare professionals realize that the health care of children poses many distinct features compared with that of the average 40-year-old adult; however, most do not comprehend that same degree of distinction exists between the health care needs of the average 40-year-old and the average 80-90-year-old adult. In current medical training, physicians spend at least threefold increased time in pediatric compared with geriatric training, and the majority receive no formal training in geriatrics at all.

Access to life-sustaining preventive care and treatments is often limited by explicit or implicit age-based criteria. In fact, access to all types of health care, ranging from routine preventive screenings (for example, mammography, colonoscopy or vaccinations) to expensive life-sustaining treatments is limited by ageist policies. Primary examples where explicit age-based 'rationing' of care have been applied include hemodialysis for end-stage kidney disease and organ transplantation. In the 1990s and 2000s, age-based rationing was implemented explicitly, particularly in countries with nationalized health insurance. One study stated: "an abundance of practical, efficiency-related and equity-oriented reasons support the use of age as the dominant limitation criterion for the benefit package of public health care insurance"7. Subsequent public outcry and lawsuits based on age discrimination led to removal of such explicit age-based criteria; however, implicit age bias remains in force, limiting access through referral patterns and other barriers. While receipt of hemodialysis has increased for those $\geq 70$ years old in the UK, this group has not received liver transplantation, and the rate of kidney transplantation remains $<9 \%$ overall in 2018-2019 despite the disproportionately higher rate of renal failure in this age group ${ }^{8}$.

Age-based rationing of critical, life-sustaining care has become explicit during the time of COVID-19. Many healthcare systems worldwide have faced critical shortages of ventilators and intensive care unit beds, and have proposed age-based rationing as the solution' However, these strictly age-based criteria clearly discriminate by age and do not allow consideration of differences in long-term prognosis, functional status and patient preferences. In the USA, age-based cut-offs have largely been rejected on the basis of age discrimination in favor of approaches that 
allocate resources based on considerations of initial severity of disease (that is, likelihood of survival of the hospitalization) and long-term prognosis (that is, likelihood of survival for $\geq 5$ years). To avoid age-based bias, consensus panels and ethics committees have recommended utilizing an interdisciplinary group for complex decision-making - including geriatric expertise and considering all evidence, along with the patient's and family's goals for care.

Older adults have been systematically excluded from randomized clinical trials. Key to the development of any efficacious and safe treatment is the testing of that treatment in the target population, which includes older adults for many conditions such as cancer as well as cardiovascular and neurological diseases. A recent systematic review of clinical trials published in leading medical journals from 1998 to 2015 found that $30 \%$ included an upper age limit and over $90 \%$ did not provide a justification for the age exclusion ${ }^{10}$. Another study of phase III clinical trials from 1965 to 2015 found upper age limits in 33\%, and $67 \%$ reported an average age that was substantially younger than the age for those affected by the disease ${ }^{11}$. In 2019, the US National Institutes of Health instituted a new policy, Inclusion across the Lifespan ${ }^{12}$, requiring older adults to be enrolled into clinical trials. Despite these safeguards, in a recent study of 847 COVID-19 vaccine and treatment trials in clinicaltrials.gov ${ }^{13}, 195$ (23\%) had an age cut-off and an additional 252 (30\%) trials had other exclusions preferentially affecting older adults; thus, 447 (53\%) of trials were considered high risk for excluding older adults. Of 18 vaccine trials, $11(61 \%)$ had age-based exclusions, while 7 (39\%) had other potential age-related exclusions; thus, $100 \%$ were considered high risk for excluding older adults. While some exclusions are necessary to protect the safety of older adults, many exclusions - such as mild stable comorbidities or the requirement for internet access - are not well-justified. Reasons for exclusion were myriad, ranging from long-standing age-related bias and discriminatory policies to paternalistic protectionism (for example, trials are too dangerous) to expediency (for example, additional time and costs to enrol older adults, or concerns about slowing safety approvals) to inadvertent age-related exclusions (for example, requiring web-conferencing). Importantly, such exclusion will limit the ability to evaluate the efficacy, dosage and adverse effects of the treatments in older adults and ultimately threaten equitable access to vaccines and treatments.

Table 1 | Creating an anti-ageist healthcare system to improve health outcomes for older adults

\begin{tabular}{|c|c|}
\hline Healthcare challenge & Potential solutions to consider \\
\hline $\begin{array}{l}\text { Atypical presentation } \\
\text { of disease }\end{array}$ & $\begin{array}{l}\text { - Highlight frequent nonspecific presentation of serious disease in older } \\
\text { adults, such as falls, delirium, dizziness and failure-to-thrive } \\
\text { - Build safety net and follow-up systems to avoid missed or delayed } \\
\text { diagnoses }\end{array}$ \\
\hline $\begin{array}{l}\text { Polypharmacy and } \\
\text { inappropriate use of } \\
\text { medications }\end{array}$ & $\begin{array}{l}\text { - Collaborate with clinical pharmacists } \\
\text { - Highlight frequent polypharmacy, adverse drug reactions, drug-drug and } \\
\text { drug-disease interactions, sensitivity to psychoactive medications and } \\
\text { need for dosage adjustments } \\
\text { - Use of Beers criteria to reduce polypharmacy and exposure to inappropriate } \\
\text { medications }\end{array}$ \\
\hline $\begin{array}{l}\text { Lack of knowledge } \\
\text { in healthcare } \\
\text { professionals }\end{array}$ & $\begin{array}{l}\text { - Training of all healthcare professionals across settings } \\
\text { - Education and training about unique aspects of clinical care in older adults } \\
\text { - Attention to implicit bias and ageism: reframe negative attitudes }\end{array}$ \\
\hline $\begin{array}{l}\text { Organ-system-based } \\
\text { approaches to clinical } \\
\text { care }\end{array}$ & $\begin{array}{l}\text { - Avoidance of sub-specialized, fragmented care } \\
\text { - Create coordinated interdisciplinary care } \\
\text { - Establish incentives for goal-directed, person-centered care guided by } \\
\text { preferences of older adults } \\
\text { - Geroscience-based approaches to maximize healthy lifespan }\end{array}$ \\
\hline $\begin{array}{l}\text { Barriers in access to } \\
\text { health care }\end{array}$ & $\begin{array}{l}\text { - Address clinical barriers, including patient-level and provider-level barriers } \\
\text { as well as insurance and financing } \\
\text { - Develop age-friendly healthcare systems globally } \\
\text { - Handle environmental barriers for those with impairments in physical or } \\
\text { cognitive function, hearing or vision, or literacy } \\
\text { - Build digital capacity for older adults } \\
\text { - Attend to social-cultural issues, including anxiety, fear and distrust } \\
\text { - Involve older adults, family caregivers and geriatricians in the solutions }\end{array}$ \\
\hline $\begin{array}{l}\text { Insufficient } \\
\text { involvement of family } \\
\text { caregivers }\end{array}$ & $\begin{array}{l}\text { - Involve family caregivers for optimal care of older adults, particularly those } \\
\text { with frailty and dementia } \\
\text { - Use of family caregivers to enhance communication, monitor treatments, } \\
\text { and improve adherence and follow-up }\end{array}$ \\
\hline $\begin{array}{l}\text { Underutilization of } \\
\text { preventive care }\end{array}$ & $\begin{array}{l}\text { - Address patient, provider and system factors that lead to underutilization } \\
\text { of effective preventive care for older adults }\end{array}$ \\
\hline $\begin{array}{l}\text { Denial of } \\
\text { life-sustaining } \\
\text { treatment }\end{array}$ & $\begin{array}{l}\text { - Utilize interdisciplinary groups including geriatric experts to consider } \\
\text { complex decision-making in access to life-sustaining treatments and } \\
\text { procedures, particularly during times of critical shortages } \\
\text { - Avoid rationing by age alone }\end{array}$ \\
\hline $\begin{array}{l}\text { Exclusion from clinical } \\
\text { trials }\end{array}$ & $\begin{array}{l}\text { - Address barriers to participation: train staff, develop alternatives to } \\
\text { internet-based participation, enlist family members for proxy consent if } \\
\text { needed and minimize exclusion for stable comorbidities } \\
\text { - Involve geriatricians in enrolment design and staff training } \\
\text { - Assure equitable access to new vaccines and therapies }\end{array}$ \\
\hline
\end{tabular}

The attitude that 'older adults are expendable ${ }^{14}$ reflects the disturbing and pervasive ageism that has been openly expressed during the time of COVID-19. In fact, undervaluing older adults endangers us all. In the context of health care, older adults are often viewed as an economic burden on resources; however, the reality is that older adults are the bedrock and foundation upon which our society is built, based on their past, current and future contributions to society and the economy. Recent economic analyses have estimated that older adults make contributions to our economy of over $\$ 250$ billion per year ${ }^{15}$. They provide family support, caregiving, paid and volunteer work, and invaluable contributions to community infrastructure globally. They are a source of experience and expertise to neighborhoods and workplaces, and represent an underutilized source of intergenerational competence and knowledge. Thus, valuing and enhancing the potential contribution of older adults to society will ultimately realize benefits across generations.

While COVID-19 has brought ageism into harsh light, it has also yielded an unprecedented opportunity to shift the paradigm and redesign an anti-ageist healthcare system which will ultimately improve health outcomes for all. With 
the upheaval of our healthcare system we have the opportunity to envision strategic, system-wide changes in how we deliver healthcare for older adults. Table 1 indicates actionable, practical solutions that will help to address the problem of ageism in health care. First and foremost, we must build age-friendly healthcare systems ${ }^{16}$ globally that include older adults, their family caregivers and geriatric experts as part of the solution. These systems must work to reduce barriers to access at all levels. Second, improved education and training of healthcare professionals will be essential to provide appropriate care targeted to the unique aspects of older adults and free of age-related bias. Such training will help to increase awareness of atypical presentation of disease in older adults and decrease polypharmacy and prescription of inappropriate medications. Providing high-quality care for older adults requires coordination and avoidance of sub-specialized, organ-system-based care. Ideally, care should be overseen by an interdisciplinary team providing person-centered care guided by the stated goals and preferences of older adults. Advancing geroscience ${ }^{17}$, which focuses on the development of biological treatments to improve health span, may help to improve healthy longevity for older adults. Involving family caregivers is important to enhance communication, monitor treatments and improve adherence and follow-up. Systematic efforts to address patient, provider and health system factors limiting utilization of preventive care will be essential for health maintenance in older adults.

Assuring just and equitable access for older adults to life-sustaining treatments and procedures is critically important in an anti-ageist framework. Accessing geriatric expertise and knowledge of the patient's preferences is essential in the complex decision-making process, particularly during times of clinical shortages. Rationing by age alone should not be the criterion. Inclusion of older adults in clinical trials is of paramount importance to ensure the effectiveness and safety of new treatments and vaccines. Strategies to enhance inclusion should include staff training, minimizing exclusions for stable conditions, involving geriatric experts in enrolment procedures, building flexible schedules and approaches for participation, and enlisting family cooperation and proxy consent. Inclusion in trials will also enhance access to the ultimate treatments and vaccines. Assuring equitable access to new vaccines and treatments by older populations, who are often disproportionately affected by the targeted diseases, is fundamental for an anti-ageist healthcare system.

The COVID-19 pandemic has brought heightened awareness of the interconnectedness of us all as individuals and as societies globally. Thus, improving care for older adults and building an optimal age-friendly healthcare system will help everyone - including our current and future selves.

\section{Sharon K. Inouye $\mathrm{e}^{1,2 \square}$ ${ }^{1}$ Department of Medicine, Beth Israel Deaconess Medical Center, Harvard Medical School, Boston, MA, USA. ${ }^{2}$ Aging Brain Center, Hinda and Arthur Marcus Institute for Aging Research, Hebrew SeniorLife, Boston, MA, USA.

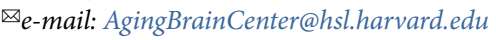

Published online: 11 February 2021

https://doi.org/10.1038/s43587-020-00004-4

References

1. Chang, E. S. et al. PLoS ONE 15, e0220857 (2020).

2. Hamel, M. B. et al. Ann. Intern. Med. 130, 116-125 (1999).

3. Limpawattana, P., Phungoen, P., Mitsungnern, T., Laosuangkoon, W. \& Tansangworn, N. Arch. Gerontol. Geriat. 62, 97-102 (2016).

4. Canto, J. G. et al. JAMA 283, 3223-3229 (2000).

5. Lavan, A. H. \& Gallagher, P. Ther. Adv. Drug Saf. 7 , $11-22$ (2016).

6. American Geriatrics Society Beers Criteria Update Expert Panel. J. Am. Geriatr. Soc. 67, 674-694 (2019).

7. Breyer, F. \& Schultheiss, C. Int. J. Health Care Finance Econ. 2, 247-264 (2002).

8. Annual Report on Kidney Transplantation 2018/19, NHS Blood and Transplant (United Kingdom National Health Service, 2019); https://nhsbtdbe.blob.core.windows.net/umbracoassets-corp/16778/nhsbt-kidney-transplantation-annualreport-2018-19.pdf

9. Miller, F. G. Why I support age-related rationing of ventilators for Covid-19 patients. The Hastings Center https://www. thehastingscenter.org/why-i-support-age-related-rationing-ofventilators-for-covid-19-patients/ (2020).

10. Thake, M. \& Lowry, A. Arch. Gerontol. Geriatr. 72, 99-102 (2017).

11. Lockett, J., Sauma, S., Radziszewska, B. \& Bernard, M. A. J. Am. Geriatr. Soc. 67, 218-222 (2019).

12. Inclusion across the lifespan. National Institutes of Health https:// grants.nih.gov/policy/inclusion/lifespan.htm\# (2019).

13. Helfand, B. K. I. et al. JAMA Intern. Med. 180, 1546-1549 (2020).

14. Schnell, F., Tahmaseb McConatha, J., Magnarelli, J. \& Fry, D. Ageism and Perceptions of Vulnerability: Framing of Age During the Covid-19 Pandemic (West Chester University, 2020).

15. Bloom, D. E., Khoury, A., Algur, E. \& Sevilla, J. P. Economist (Leiden) 168, 153-181 (2020).

16. Fulmer, T., Mate, K. S. \& Berman, A. J. Am. Geriatr. Soc. 66 , $22-24$ (2018)

17. Barzilai, N., Cuervo, A. M. \& Austad, S. JAMA 320 , 1321-1322 (2018).

7 Acknowledgements

This work was supported in part by the National Institute on Aging (grant nos. P01AG031720 and R24AG054259). S.K.I. holds the Milton and Shirley F. Levy Family Chair at Hebrew SeniorLife/Harvard Medical School. The funding sources had no role in the design, conduct or reporting of this Comment.

Competing interests

The author declares no competing interests. 